Core Books in Advanced Mathematics

\title{
Coordinate Geometry and Complex Numbers
}




\section{Core Books in Advanced Mathematics}

General Editor: C. PLUMPTON, Moderator in Mathematics, University of London School Examinations Department; formerly Reader in Engineering Mathematics, Queen Mary College, University of London.

Titles available

Coordinate Geometry and Complex Numbers

Methods of Trigonometry

Newton's Laws and Particle Motion

Mechanics of Groups of Particles

Proof

Differentiation

Integration

Vectors

Curve Sketching 


\section{Core Books in Advanced Mathematics}

\section{Coordinate \\ Geometry and \\ Complex Numbers}

\section{P. S. W. Macllwaine}

formerly Chief Examiner in Advanced Level Mathematics, University of London School Examinations Department, and Head of Mathematics, Sutton Valence School.

\section{Plumpton}

Moderator in Mathematics, University of London School Examinations Department; formerly Reader in Engineering Mathematics, Queen Mary College, University of London.

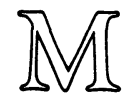

Macmillan Education 
(C) P. S. W. MacIlwaine and C. Plumpton 1984

All rights reserved. No part of this publication may be reproduced or transmitted, in any form or by any means, without permission.

First published 1984

Published by

Macmillan Education Limited

Houndmills Basingstoke Hampshire RG21 2XS

and London

Associated companies throughout the world

Typeset in Hong Kong by Asco Trade Typesetting Ltd.

ISBN 978-0-333-36253-2

ISBN 978-1-349-07012-1 (eBook)

DOI 10.1007/978-1-349-07012-1 


\section{Contents}

Preface

vii

1 Basic results and techniques

Elementary results in coordinate geometry; Loci; The equation of a circle; Parametric equations

\section{Conics}

Conics; The parabola; The ellipse; The hyperbola; The rectangular hyperbola; The line-pair through the origin

\section{Polar coordinates, matrices and transformations}

Polar coordinates; Loci in polar coordinates; Area of a sector of a polar curve; Use of matrices to represent linear transformations; Use of the unit square to identify transformations

\section{Complex numbers}

How numbers have developed; Operations on complex numbers; Conjugate complex numbers; The Argand diagram; Modulus and argument; Distance and direction on the Argand diagram; Loci on the Argand diagram; Product and quotient for complex numbers in modulus-argument form; De Moivre's Theorem

Answers

Index 


\section{Preface}

Advanced level mathematics syllabuses are once again undergoing changes in content and approach following the revolution in the early 1960s which led to the unfortunate dichotomy between 'modern' and 'traditional' mathematics. The current trend in syllabuses for Advanced level mathematics now being developed and published by many GCE Boards is towards an integrated approach, taking the best of the topics and approaches of modern and traditional mathematics, in an attempt to create a realistic examination target through syllabuses which are maximal for examining and minimal for teaching. In addition, resulting from a number of initiatives, core syllabuses are being developed for Advanced level mathematics consisting of techniques of pure mathematics as taught in schools and colleges at this level.

The concept of a core can be used in several ways, one of which is mentioned above, namely the idea of a core syllabus to which options such as theoretical mechanics, further pure mathematics and statistics can be added. The books in this series are core books involving a different use of the core idea. They are books on a range of topics, each of which is central to the study of Advanced level mathematics, which together cover the main areas of any single-subject mathematics syllabus at Advanced level.

Particularly at times when economic conditions make the problems of acquiring comprehensive textbooks giving complete syllabus coverage acute, schools and colleges and individual students can collect as many of the core books as they need to supplement books they already have, so that the most recent syllabuses of, for example, the London, Cambridge, AEB and JMB GCE Boards can be covered at minimum expense. Alternatively, of course, the whole set of core books gives complete syllabus coverage of single-subject Advanced level mathematics syllabuses.

The aim of each book is to develop a major topic of the single-subject syllabuses giving essential book work, worked examples and numerous exercises arising from the authors' vast experience of examining at this level. Thus, as well as using the core books in either of the above ways, they are ideal for supplementing comprehensive textbooks by providing more examples and exercises, so necessary for the preparation and revision for examinations.

In this book, we cover the requirements of the non-specialist mathematician in coordinate geometry and complex algebra in accordance with the core syllabus of pure mathematics now being included by GCE Examining Boards at Advanced level and meeting the requirements of the polytechnics and universities for entrants to degree courses in mathematics-related subjects. 
In the use of coordinates, the importance of technique, that is the choice of a suitable method to tackle a problem, has been stressed. The statement and proof of standard properties of conics has been kept to a minimum, or covered by worked examples. While inevitably lacking experience, the student should try to acquire and appreciate good technique, so that more difficult problems can be tackled confidently. Only the most elementary knowledge of coordinates has been assumed, and important basic results are listed for easy reference.

In the section on complex algebra no previous knowledge is assumed; the intention is to show the usefulness of complex numbers rather than give a rigorous development of their properties from a set of axioms. On the other hand, in accordance with modern attitudes, the underlying structure of the complex field has been indicated so that the student can pursue this aspect further if desired.

Plenty of examples are provided throughout the book, both as exercises and as part of the text; the worked examples sometimes make comparisons between good and bad methods.

P. S. W. MacIlwaine
C. Plumpton 